\title{
Interannual stability of phytoplankton community composition in the North-East Atlantic
}

\author{
Stephanie Allen ${ }^{1,6, *}$, Stephanie Henson ${ }^{2}$, Anna Hickman ${ }^{1}$, Claudie Beaulieu ${ }^{3}$, \\ Patrick C. Doncaster ${ }^{4}$, David G. Johns ${ }^{5}$ \\ ${ }^{1}$ Ocean and Earth Sciences, University of Southampton, National Oceanography Centre, Southampton SO14 3ZH, UK \\ ${ }^{2}$ National Oceanography Centre, Southampton SO14 3ZH, UK \\ ${ }^{3}$ Earth and Marine Sciences, University of California Santa Cruz, Santa Cruz, CA 95064, USA \\ ${ }^{4}$ Biological Sciences, University of Southampton, Southampton SO17 1BJ, UK \\ ${ }^{5}$ Marine Biological Association, The Laboratory, Citadel Hill, Plymouth PL1 2PB, UK \\ ${ }^{6}$ Present address: Plymouth Marine Laboratory, Prospect Place, West Hoe, Plymouth PL1 3DH, UK
}

\begin{abstract}
As primary producers, phytoplankton play a pivotal role in the marine environment and are central to many biogeochemical processes. Changes to phytoplankton community composition could have major consequences for wider ecosystem functioning and may occur in response to climate change. Here we describe multi-decadal variability in phytoplankton community structure using taxonomic data from the Continuous Plankton Recorder collected in the North-East Atlantic from 1969-2013, using a total of 42 diatom and dinoflagellate taxa. We considered a range of characteristics of community structure, including taxonomic diversity and community stability and disorder, and how these characteristics change in response to sea surface temperature, mixed layer depth and the North Atlantic Oscillation. We found that phytoplankton community composition was largely stable on interannual timescales. A change in community composition occurred between 1985 and 1995 due to an increased dominance of 2 diatom taxa (Rhizosolenia styliformis and Thalassiosira spp.); however, after this period, the community returned to its previous composition. Further, a community disorder analysis found that phytoplankton compositional structure became more rigid in recent years, which may lead to an eventual community shift in the future. In contrast to previous studies that revealed relationships between total phytoplankton abundance or biomass and environmental forcing, we found that community structure had, at most, a very weak relationship with the environmental parameters tested. Changes to the physical environment may therefore have less influence at interannual timescales on phytoplankton community structure than previously thought.
\end{abstract}

KEY WORDS: Phytoplankton - Continuous - Plankton recorder - Bray-Curtis - Biodiversity · Disorder $\cdot$ Long-term analysis $\cdot$ Community structure $\cdot$ Stability

\section{INTRODUCTION}

The stability of community taxonomic composition largely depends on the capacity for individual taxa to withstand perturbation, with external forcing capable of altering a community over multiple spatio-temporal

*Corresponding author: stephroseallen@gmail.com scales (Beaugrand \& Ibanez 2002, Edwards \& Richardson 2004, Beaugrand et al. 2008). Because phytoplankton have many ecological and biogeochemical functions, the alteration of taxa within a community in response to global climate change may have the potential to alter global biogeochemical cycles, ecosys- 
tem functioning and predator-prey relationships, causing trophic mismatch (Edwards \& Richardson 2004, Beaugrand et al. 2008, Eggers et al. 2014).

In a community of taxa with similar resource needs, the community composition can be maintained through trade-offs between intrinsic population growth capacity and competitive impact through growth rates and nutrient affinity (Dakos et al. 2009, Doncaster et al. 2016). During periods of exogenous forcing, ecological theory predicts an initial rise of dominant competitors, which may take 'keystone' roles that impose structural rigidity on the community (Doncaster et al. 2016). Ongoing exogenous forcing eventually disadvantages slow-replicating taxa, generally including the dominant competitors, tipping the community into a more fluid structure with prevalence of fast-replicating 'weedy' taxa (Wang et al. 2019). Analysis of temporal variations in community composition may thus provide an early warning signal of exogenous forcing affecting the community (Beaugrand \& Reid 2003, Edwards \& Richardson 2004, Beaugrand et al. 2008, Doncaster et al. 2016).

Due to the diverse role that phytoplankton play in the marine environment, much research has been devoted to fluctuations in the abundance, biomass and community composition of these organisms (Dutkiewicz et al. 2001, Beaugrand \& Reid 2003, Sommer \& Lengfellner 2008). Current work concerning longterm variability in phytoplankton populations has predominantly focussed on the abundance and biomass of the entire phytoplankton population or large functional groups within it, such as diatoms and dinoflagellates (Edwards 2001, Henson et al. 2009, Barton et al. 2015). For example, seasonal changes in North Atlantic phytoplankton have been well documented, and a significant fraction of the variability in functional groups has been attributed to fluctuations in the physical environment (Follows \& Dutkiewicz 2001, Dandonneau et al. 2004, McQuatters-Gollop et al. 2007a). The physical environment has also been implicated as the dominant factor driving population fluctuations over interannual timescales (Beaugrand \& Reid 2003, Leterme et al. 2005); however, this remains under debate, with some studies concluding that predator-prey and other ecological interactions drive the variability (Benincà et al. 2008, Dakos et al. 2009, Boeing 2016). The variability of phytoplankton on longer timescales (multi-decadal, geological) is less studied, especially in regard to shifts in community composition (Cermeño et al. 2008).

Sea surface temperature (SST) directly impacts phytoplankton growth and metabolic rates (Eppley 1972) and indirectly impacts phytoplankton abun- dance by altering stratification and thus light and nutrient availability (Edwards \& Richardson 2004). Interannual variability in bulk phytoplankton biomass across the North Atlantic basin has been associated with increased SST, particularly in the sub-polar gyre region (Colebrook 1982, Beaugrand \& Reid 2003, Beaugrand et al. 2008, Barton et al. 2015). Further, dinoflagellates have been shown to outcompete diatoms (on average) in warmer years (Boyd et al. 2010, Henson et al. 2012, Zhai et al. 2013). Temporal variability in the mixed layer depth (MLD) also influences the magnitude and composition of phytoplankton communities. In a model study, longer periods of stratification and shallower mixed layers increased diatom, coccolithophore and prasinophyte biomass compared with years of frequent deep mixing (Litchman et al. 2006). Observational studies have also linked shallower mixed layers to the dominance of smaller protist taxa over haptophytes (van de Poll et al. 2013, Brun et al. 2015).

Multi-decadal variability in North Atlantic phytoplankton abundances has also been linked to a basin-wide climatic oscillation, the North Atlantic Oscillation (NAO). The NAO index is a measure of the difference in sea level pressure between the Azores and Iceland, which results in shifts to atmospheric circulation causing broad changes to the physical ocean environment (Hurrell 1995). The phase of the NAO index is correlated with changes in the relative abundance of diatoms, which increase in the North-East Atlantic during positive NAO phases, typical of cooler conditions with deeper mixed layers (Henson et al. 2012). Conversely, dinoflagellates dominate in warmer conditions during negative NAO periods in the sub-polar region of the North Atlantic (Edwards 2001, Henson et al. 2012). Long-term positive trends in phytoplankton biomass have also been associated with long-term trends in the NAO index, suggesting that atmospheric variability may be a key driving factor in phytoplankton variability on interannual to decadal timescales (Barton et al. 2003, Henson et al. 2012, Zhai et al. 2013).

Investigations into multi-decadal-scale variability in North Atlantic phytoplankton using in situ observations have tended to focus on bulk phytoplankton properties such as total biomass or productivity (Edwards 2001, Beaugrand et al. 2008), while studies exploring community composition generally focus on functional groups (Litchman et al. 2006, Boyd et al. 2010, Barton et al. 2016).

In this study, we analysed multi-decadal variability in the North Atlantic diatom and dinoflagellate community composition using data from the Continuous 
Plankton Recorder (CPR) survey from 1969-2013. The CPR survey provides a unique multi-decadal view of plankton across the North Atlantic basin that resolves individual taxa, and has followed a consistent sampling methodology since 1948 for phytoplankton and 1958 for zooplankton. We consider several ecological metrics describing the observed diatom and dinoflagellate community, which is hereafter is referred to as the 'phytoplankton community', and relate the temporal variability in these metrics to 3 environmental drivers: SST, MLD and the NAO index. The aim of this study was to evaluate the stability of phytoplankton composition in the North-East Atlantic, an environment that has changed substantially over the past half century, by testing the following hypotheses: (1) there was no significant, persistent change in the diversity and structure of the phytoplankton community in the North-East Atlantic between 1969 and 2013; and (2) there is no relationship between phytoplankton community structure and SST, MLD or NAO index in the North-East Atlantic.

\section{MATERIALS AND METHODS}

\subsection{Phytoplankton community composition}

The area of study is defined by 4 CPR Standard Areas (B5, C5, D5 and E5, Fig. 1). This region encompasses sections of the temperate and sub-polar regions of the North Atlantic.

Information on phytoplankton taxa abundance was obtained from the CPR survey, part of the Marine Biological Association (the CPR survey was previously managed by the Sir Alister Hardy Foundation for Ocean Science), Plymouth. The CPR device is towed behind a 'ship of opportunity', usually at speeds of 15-20 knots at a depth of $\sim 7$ m (Richardson et al. 2006). Plankton were captured on a moving silk layer (mesh size $270 \mu \mathrm{m}$ ), preserved by the application of a second silk layer and stored in a tank containing $4 \%$ formaldehyde. Each CPR sample consists of a $15 \mathrm{~cm} \times 10.5 \mathrm{~cm}$ section of silk, representing 10 nautical miles of tow. Due to the scale and spatial coverage of the CPR survey, phytoplankton cells are recorded as present or absent across 20 microscopic fields of view, from which abundances are calculated in accordance with the number of counts (Richardson et al. 2006). Due to the large mesh size of the CPR device, smaller phytoplankton taxa are likely under-sampled, although organisms as small as coccolithophores are regularly recorded (RiveroCalle et al. 2015). Larger phytoplankton, such as armoured dinoflagellates and chain-forming diatoms, are better sampled (Edwards et al. 2013). Data from the CPR survey are therefore regarded as semiquantitative, and are best used at monthly or annual temporal resolution (Richardson et al. 2006). Here we focus on dinoflagellate and diatom taxa composition at the annual scale and refer to the sub-set of the total community that the CPR samples as the 'phytoplankton community'. For additional information on the CPR methodology and history, see Barnard et al. (2004), Reid et al. (2003) and Richardson et al. (2006).

A total of 30281 samples used in the analysis were collected between 1969 and 2013 across 4 standard CPR areas of the North-East Atlantic (Fig. 1, Table 1). The time period 1969-2013 was chosen because the sampling effort was sufficient for annual interpolation of the data. Within these years, if a year contained $<8$ mo of data it was removed from further analysis

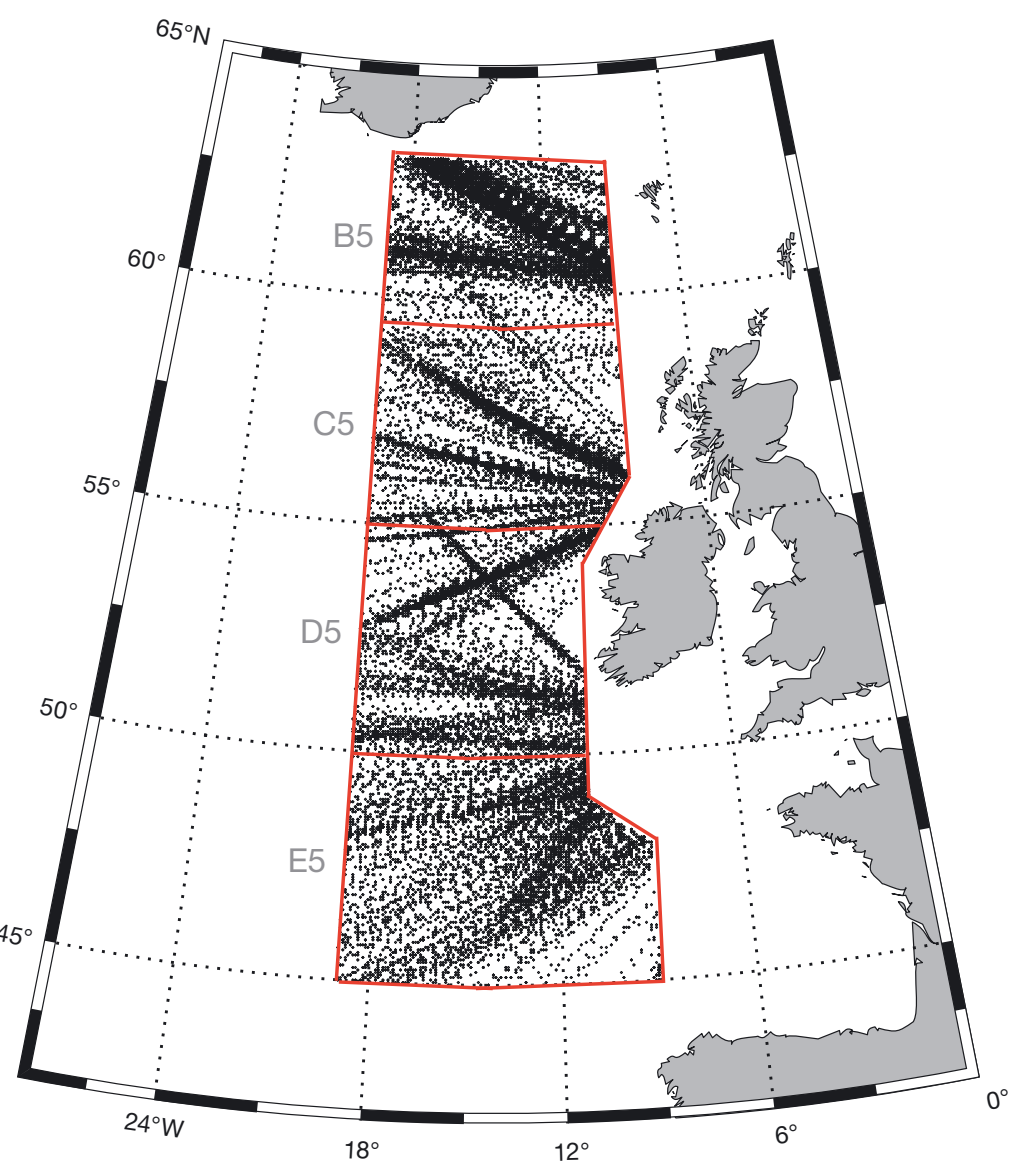

Fig. 1. Study site in the North-East Atlantic $\left(45^{\circ}-63^{\circ} \mathrm{N}, 10^{\circ}-20^{\circ} \mathrm{W}\right)$. The Continuous Plankton Recorder (CPR) standard areas are highlighted in red, and the individual samples collected by the CPR survey are represented by black dots 
Table 1. Number of data points and percentage of missing months over the study period of 1969 to 2013 for each Continuous Plankton Recorder (CPR) standard area

\begin{tabular}{|ccc|}
\hline & $\begin{array}{c}\text { Number of data } \\
\text { points }\end{array}$ & $\begin{array}{c}\text { Percentage of missing } \\
\text { months }\end{array}$ \\
\hline B5 & 10076 & 13.1 \\
C5 & 7196 & 30.0 \\
D5 & 6440 & 42.0 \\
E5 & 6569 & 23.1 \\
\hline
\end{tabular}

(resulting in the time series containing 43 years in region B5, 29 years in C5, 22 years in D5 and 36 years in E5). Data within the remaining years were linearly interpolated to create an annual mean abundance for each phytoplankton taxon (Colebrook 1975), unless 2 or more consecutive years were missing data. Phytoplankton abundances were then fourth-root transformed to reduce the influence of the most dominant taxa (Clarke et al. 2008), and all taxa with a frequency of $<1 \%$ for all CPR samples were removed from the dataset. By removing taxa that contributed to $<1 \%$ of the community, smaller and poorly sampled taxa such as coccolithophores were removed from the CPR dataset. Our statistical analysis of community composition therefore focusses on diatoms and dinoflagellates, organised in a community matrix of up to 45 years by 42 taxa for each region.

Phytoplankton colour index (PCI) data from the CPR survey were also included in our analysis. PCI is a visual assessment of the 'greenness' of the silk ('nil', 'very pale green', 'pale green' and 'green') that is subsequently assigned numerical values based on acetone extracts using spectrophotometric methods (Richardson et al. 2006). PCI data have been previously verified using satellite data (Raitsos et al. 2005, 2014). The PCI is used as a semi-quantitative assessment of total community biomass, which accounts for diatoms and dinoflagellates, as well as other microand nano-flagellates that were destroyed or too damaged for taxa identification while nevertheless contributing to the retained pigments (Richardson et al. 2006).

\subsection{Environmental data}

Vertical profiles of ocean temperature and salinity were obtained from the Hadley Centre's EN4 qualitycontrolled dataset (at $1^{\circ}$ resolution, downloaded from www.metoffice.gov.uk/hadobs/en4/) (Ingleby \& Huddleston 2007, Good et al. 2013). Density was calcu- lated from monthly temperature and salinity values, and MLD was defined as the depth at which a density difference of $>0.125 \mathrm{~kg} \mathrm{~m}^{-3}$ from the surface was observed (Chiswell 2011, Chiswell et al. 2013). Annual averages were calculated for both SST and MLD values to correspond with the data from the CPR survey.

The NAO index time series was obtained from the UCAR Climate Analysis Section (Hurrell et al. 2003, https://climatedataguide.ucar.edu/climate-data/ hurrell-north-atlantic-oscillation-nao-index-pcbased). The NAO index used was the principal component based time series of surface pressure differences between the Azores and Iceland (Hurrell 1995). For the present study, we used an average of the NAO index for the months December, January, February and March of each year.

Nutrients were not used as an environmental factor in this study, because, although they were considered in the design, data were not available over the appropriate time and space scales to compare with the CPR data for all regions. As such, only physical parameters of the environment were retained for analysis.

\subsection{Statistical analysis}

Different statistical analyses were used to explore changes in community composition, relationships to environmental forcing and the stability and potential for change within the phytoplankton community over time. Analysis was undertaken using R version 3.3.2 (R Core Team 2016) and MatLab version R2019b (The MathWorks).

\subsubsection{Characterizing long-term changes}

To characterize temporal patterns and determine the presence of temporal changes in the SST and PCI time series, a combination of trend detection and change-point analysis was used. We used an approach that compares 8 models that are commonly used to represent environmental time series: (1) a constant mean (no change), (2) a constant mean with background autocorrelation, (3) a long-term trend, (4) a long-term trend with background autocorrelation, (5) change points in the mean, (6) change points in the mean with background autocorrelation, (7) change points in the slope of the trend and (8) change points in the slope of the trend with background autocorrelation (Beaulieu \& Killick 2018). The models with change points were fitted using the pruned exact linear time algorithm developed by Killick et al. (2012). 
To select the best model to characterize a time series, we used Akaike's information criterion (AIC). The smallest AIC value indicates the best model fit and the AIC difference between models is a measure of how significant the differences are (Beaulieu \& Killick 2018, Killick et al. 2018). The R package 'EnvCpt' (Killick et al. 2018) automates the fit and selection between models. Results of EnvCpt analysis were used to identify change points and trends in the physical environment that may be linked to changes in the phytoplankton community.

\subsubsection{Analysis of community composition}

To evaluate changes in community composition over time, Bray-Curtis dissimilarity coefficients $\left(C_{n}\right)$ were calculated for each of the $4 \mathrm{CPR}$ regions of the North Atlantic (Bray \& Curtis 1957, Anderson et al. 2011, Legendre \& Legendre 2012). This technique calculates a diversity measure that accounts for both the presence and abundance of taxa:

$$
C_{n}=\left(\frac{2 w}{n_{a}+n_{b}}\right)
$$

where $n_{a}$ is the total number of individuals in year $a$, $n_{b}$ is the total number of individuals in year $b$, and $2 w$ is the sum of the lowest value of abundances for taxa found in both year $a$ and year $b$ (Bray \& Curtis 1957). Bray-Curtis analysis matches abundances at a taxonby-taxon level, comparing each year to all other years in pairwise testing. Resulting values of $C_{n}$ range between 0 ( 2 identical communities) and 1 (2 entirely different communities) and take account of both the presence and abundance of taxa within a sample.

\subsubsection{Relationship between phytoplankton composition and the physical environment}

For each environmental variable, a dissimilarity matrix was produced in order to apply a Mantel test (Mantel 1967) that evaluates the relationship between the phytoplankton community structure and the environment. The Mantel test is a pairwise correlation to test the null hypothesis that there is no relationship between 2 dissimilarity matrices (i.e. community data and an environmental parameter):

$$
Z_{M}=\sum_{a=1}^{N-1} \sum_{b=a+1}^{N} \boldsymbol{C}_{n 1 a b} \boldsymbol{C}_{n \mathbf{n} a b}
$$

where $\boldsymbol{C}_{\boldsymbol{n} 1}$ and $\boldsymbol{C}_{\boldsymbol{n} 2}$ are 2 dissimilarity matrices with $N$ samples, in which $\boldsymbol{a}$ and $\boldsymbol{b}$ are row and column in- dices, the first being the community dissimilarity matrix and the second an environmental parameter. The resulting correlation coefficient, $Z_{M}$, ranges between -1 (a strong negative correlation) and 1 (a strong positive correlation), with 0 as no correlation and a pvalue indicating the significance of the relationship.

\subsubsection{Analysis of taxon dominance}

To further examine the structure of the phytoplankton community, the dominance of each taxon was calculated as the percentage contribution of an individual taxon to the total abundance. Taxon dominance allows for examination of interannual changes in specific taxa, as opposed to the whole community quantified in Bray-Curtis analysis.

\subsubsection{Analysis of community stability}

To assess the stability and potential for change within the phytoplankton community, 2 metrics were applied to each of the 4 standard areas of the NorthEast Atlantic. The first metric is a measure of resilience defined as the rate of return of a community to its mean state after a disturbance (Pimm 1984). Communities with a high resilience to change demonstrate fast return times, whereas communities with lower resilience take longer to return to their mean state (Dakos et al. 2012, De Keersmaecker et al. 2014). In this study, the temporal relationship between the observed years is used as a measure of resilience, and is expressed through the first-order autocorrelation, defined as when consecutive errors are correlated. For the taxonomic time series, $t s_{A}$, with $N$ observations from time $t_{1}$ to $t_{N \text {, the resilience }}$ of a community is calculated as:

$$
1-\rho_{1}=\frac{\sum_{i=2}^{N}\left[t s_{A}(i)-\overline{t s_{A}}\right]\left[t s_{A}\left(i_{-1}\right)-\overline{t s_{A}}\right]}{\sum_{i=1}^{N}\left[t s_{A}(i)-\overline{t s_{A}}\right]^{2}}
$$

where $t s_{A}$ is the ecological time series (here the abundance of each diatom and dinoflagellate), and $t s_{A}(i)$ is the time series at time $i$ (adapted from Dakos et al. 2012, De Keersmaecker et al. 2014). The resilience metric ranges between 0 and 1 ; the lower the value of $\rho_{1}$, the more resilient a community is to disturbance and the faster it will return to its mean state after a disturbance.

The second test of resilience is a test of ecological variance, used to assess the stability of a community. Ecological variance is defined as the total variability of a community and provides a more general meas- 
ure of ecological stability than measures such as resilience (De Keersmaecker et al. 2014). The coefficient of variance $(V)$ is calculated as:

$$
V=\frac{S\left(t s_{A}\right)}{\overline{t s_{A}}}
$$

where $t s_{A}$ is the ecological time series and $S$ is its standard deviation. Variance was normalised to the average of the time series $\left(\overline{t{s_{A}}_{A}}\right)$ in order to aid comparison between sampled regions. Communities were deemed to have a relatively large sensitivity to change in the environment if they take a longer time to return to equilibrium after a disturbance and demonstrate a higher variance than less sensitive communities.

\subsubsection{Analysis of community disorder}

Community disorder $\left(D_{0}\right)$ provides a method of evaluating changes in functional composition (Thébault \& Fontaine 2010, Doncaster et al. 2016). When community composition is disordered through time, the structure of the community is influenced by an unpredictable turnover of taxa. We analysed disorder following methods detailed by Doncaster et al. (2016), using the $\mathrm{R}$ function 'nestedtemp' in the 'vegan' library (Oksanen \& Carvalho 2013, R Core Team 2016).

Each disorder value was calculated from an $m \times n$ matrix of community incidence comprising $m=10$ consecutive years with $n$ total taxa present in 1 or more of the 10 years. The matrix was shuffled to order the years (in rows) by descending abundance from top to bottom and the taxa (in columns) by descending prevalence from left to right. A perfectly ordered matrix would have all presences in the top left, and all absences in the bottom right. The resulting divide between these 2 extremes is known as the 'threshold of perfect fill', and is calculated as:

$$
y=\left(1-[1-x]^{c}\right)^{1 / c}
$$

for matrix coordinates $(x, y)$ with $c$ selected to create a curve that integrates to the same area as the proportion of presences (Oksanen \& Carvalho 2013). Any observed presence to the right of the threshold, or absence to the left, is classified as an anomalous observation, and disorder is quantified as a function of the sum across all observations of these anomalies. Values of disorder range between 0 for a perfectly ordered community to 100 for a completely disordered community (Rodriguez-Girones \& Santamaria 2006). In a perfectly ordered community $\left(D_{0}=0\right)$, the year in the bottom row of the matrix has a taxa composition that is a perfectly ordered subset of the composition in the year above it in the matrix, and so on through all of the years. This means that community composition in any year is determined by an ordered accumulation and/or attrition of taxa from previous years. In contrast, complete disorder $\left(D_{0}=100\right)$ means that the taxa composition in one year provides no information about composition in the year for the rows above or below in the matrix.

While disorder measures the unpredictability of community composition through time, biodiversity quantifies the number of species. Disorder and diversity values were calculated and correlated in order to inform on the relative frequency of occurrence of commonly abundant species. For each year of available data, disorder values were tested for correlation with both taxa richness, defined as the number of taxa present, and with Hill's $N_{2}$ biodiversity parameter, which considers the richness and evenness of the community (Hill 1973):

$$
N_{2}=\frac{1}{\sum_{\alpha=1}^{n} A_{\alpha}^{2}}
$$

where $A$ is the proportional abundance of taxon $\alpha$ in a community of $n$ taxa, with abundance given by the square-root percentage presence (using the R package 'vegan', Oksanen \& Carvalho 2013). Both taxa richness $(R)$ and biodiversity $\left(N_{2}\right)$ were calculated at the last time point in the matrix used for each $10 \mathrm{yr}$ period disorder calculation. Correlations were calculated using Pearson's correlation on paired first differences in biodiversity (or taxa richness), and disorder values were calculated for consecutive years over the time series (e.g. 1970-1969, 1971-1970, etc.). It must be noted that this analysis required a time series without gaps. Consequently, data from 45 consecutive years (1969-2013) were used in region B5, 32 yr (1969-2000) in region C5, 20 yr (1969-1988) in region D5 and 45 yr (1969-2013) in region E5. Other years from C5, D5 and E5 that could not be interpolated were discarded.

The sequential correlation coefficients between richness $(R)$ and disorder $\left(D_{0}\right)$ provide information on the relative occurrence of different types of taxa. A prolonged period of negative coefficients indicates a dominance of more persistent taxa over ephemeral taxa, as upward fluctuations in biodiversity are associated with an ordered accumulation of taxa and downward fluctuations with disordered turnover. In communities of taxa that compete for similar resources, the most persistent taxa are likely to function as keystones, which shape community composi- 
tion through strong inter-specific interactions (Doncaster et al. 2016). A switch from negative coefficients to a period of positive coefficients indicates a change to an ordered sequence of losses and disordered gains, consistent with exogenous forcing and a prevalence of fast-replicating weedy taxa (Doncaster et al. 2016).

\section{RESULTS}

\subsection{Temporal change in the physical environment and PCI}

All physical parameters displayed interannual and decadal variability (Fig. 2). In particular, SST showed an increasing trend, with all regions displaying an eventual change to a warmer regime (Fig. 2a). However MLD remained between 35 and 65 m (Fig. 2b), and the NAO varied widely, spanning from its lowest values in 1969 and 2010 of -2.5 to its largest value in 1990 of +2.5 (Fig. 2c). The EnvCpt analysis conducted on the SST time series indicated that region B5 had an overall increasing trend with a change point in 1978, whereas regions C5, D5 and E5 all showed a change point in the mean during 1994 that shifted the environment to a warmer regime.

The time series of the PCI anomalies demonstrated an overall increasing trend in all regions (Fig. 3). Analysis of the PCI time series using the 8 models tested via the EnvCpt framework revealed structural changes for each region throughout the time series. The best fit model for the PCI time series within regions B5 and C5 indicated a change in the mean of the time series, with change points in 1997 for region B5 and 1984 for region C5 (Fig. 3). Small AIC values for this model suggest a good fit in the model choice (Fig. 4). The region D5 time series was best modelled as mean with autocorrelation (model 2, constant mean with autocorrelation); however, the AIC value for this region was similar to model 6 , which indicated a change point. The most robust model for the time series in region E5 was model 7, which indicated a trend with a change point in 1978 (Fig. 4).

\subsection{Temporal change in community composition}

Bray-Curtis dissimilarity coefficients describe variability in the phytoplankton community structure, accounting for changes in taxa presence and abundance through time. The Bray-Curtis analysis revealed clear interannual variability in the phyto-
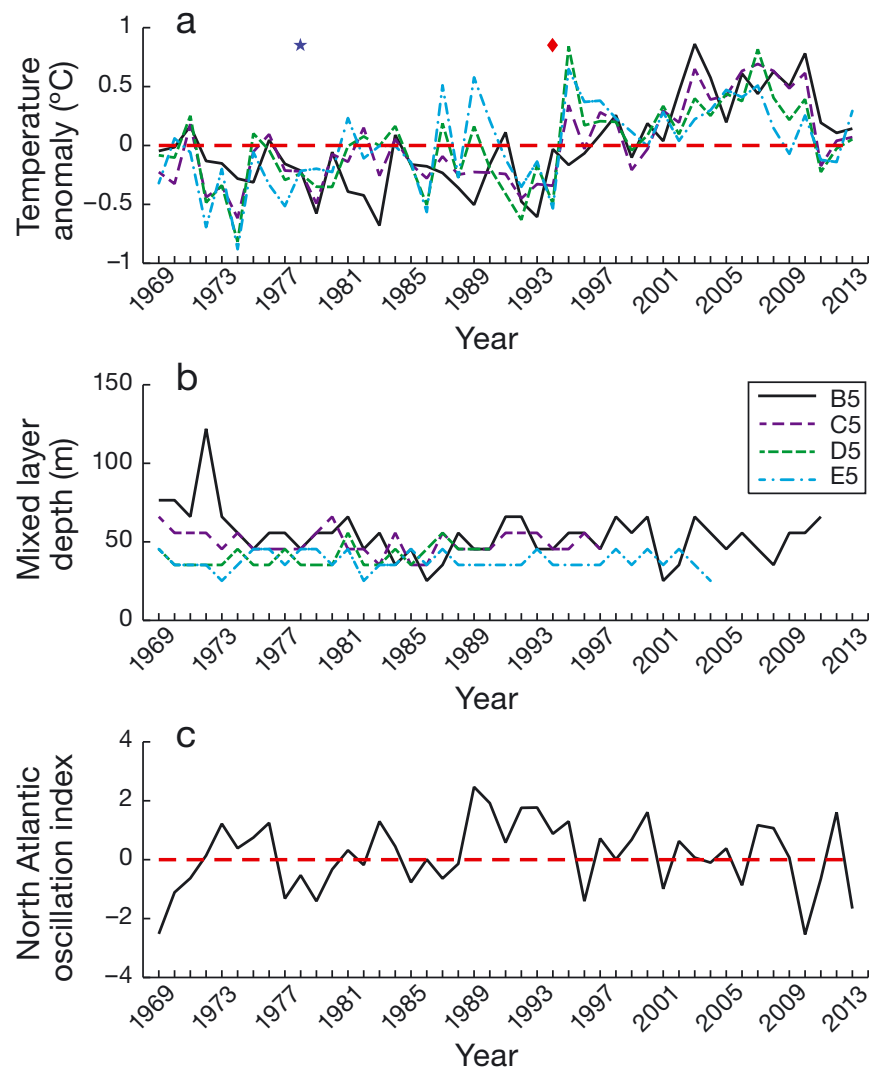

Fig. 2. Variability in the physical environment for each Continuous Plankton Recorder (CPR) region over the study period 1969-2013. (a) Sea surface temperature anomalies, (b) mixed layer depth and (c) principal component-based North Atlantic Oscillation index (Hurrell et al. 2003, Ingleby \& Huddleston 2007). The blue star marks a change point in 1978 for region B5, and the red diamond marks a change point in 1994 for regions C5, D5 and E5

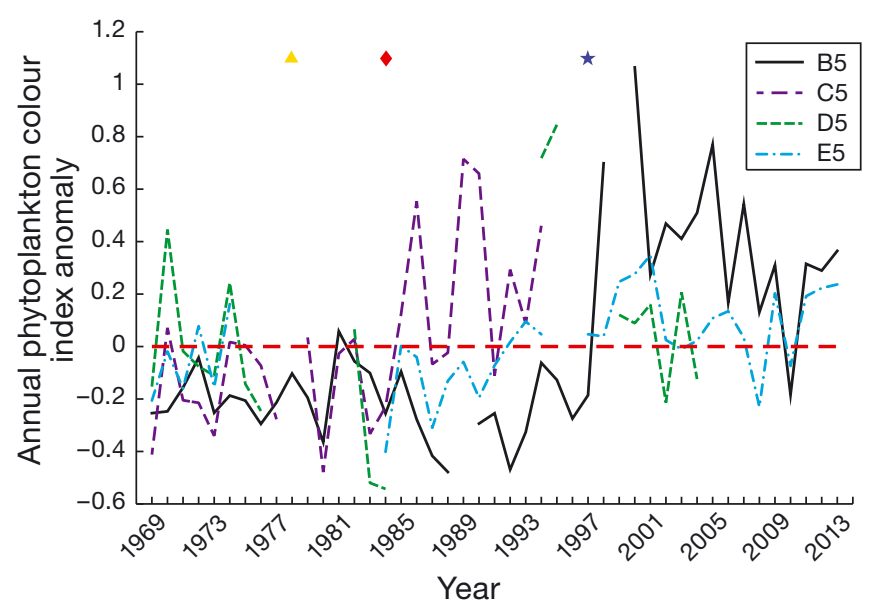

Fig. 3. Phytoplankton colour index (PCI) anomalies for each Continuous Plankton Recorder (CPR) region over the study period 1969-2013. The yellow triangle marks a change point in the trend for region E5 in 1978, the red diamond marks a change point in the mean for region C5 in 1984, and the blue star marks a change point in the mean for region B5 in 1997 

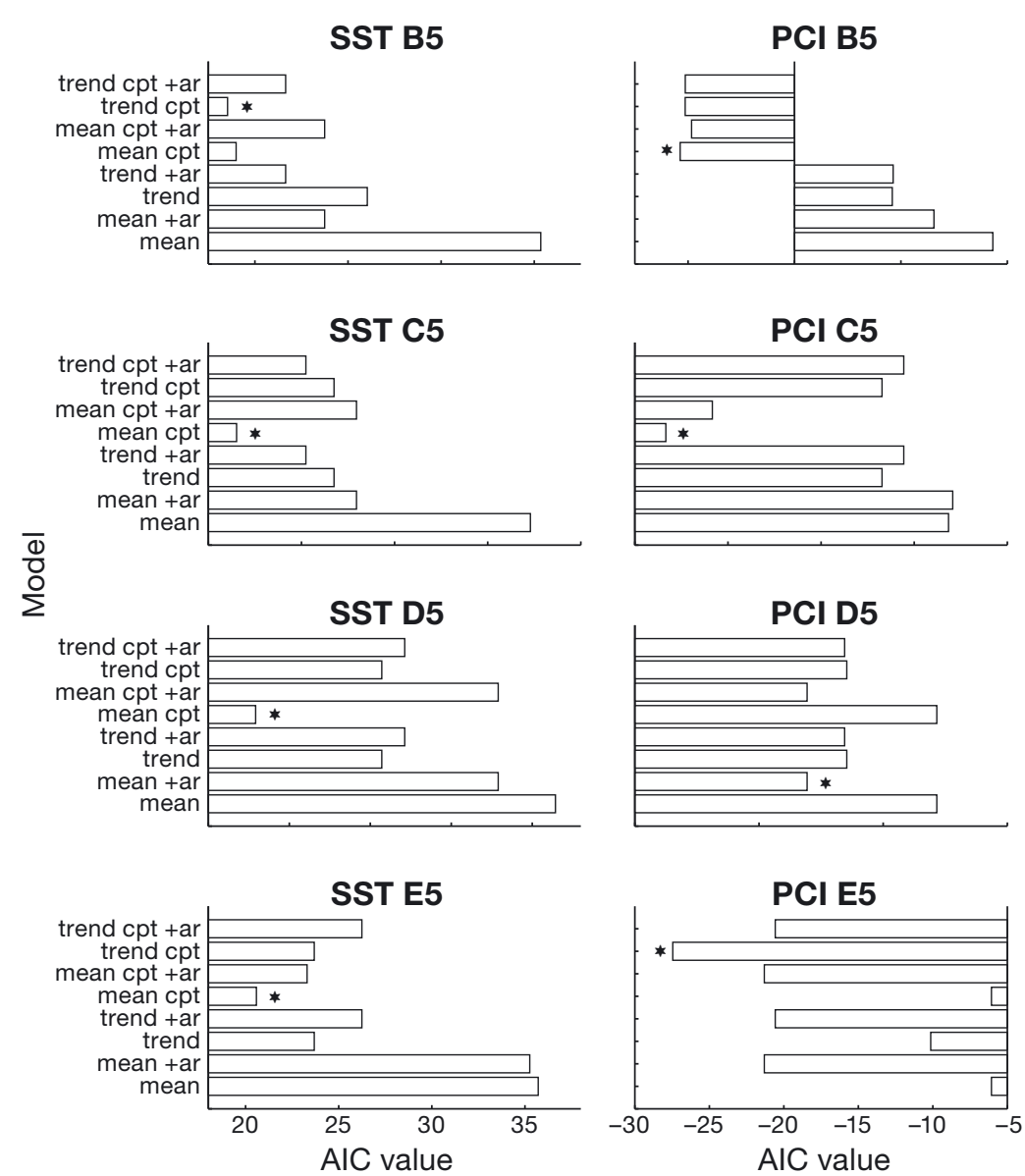

Fig. 4. Akaike's information criterion (AIC) from 'EnvCpt' analysis (used to identify change points and trends in the physical environment) for both sea surface temperature (SST) and phytoplankton colour index (PCI) in all regions of the North-East Atlantic. Small AIC values for a model suggest a good fit; * model of best fit. cpt: change point; ar: autocorrelation statistically significant at the $95 \%$ level $(\mathrm{p}<0.05)$. The strongest correlation was between the Bray-Curtis dissimilarity coefficients and PCI, which was to be expected between 2 associated biological datasets $(\mathrm{r}=0.31)$. This result demonstrates that PCI, used as a proxy for phytoplankton biomass, correlates weakly with the taxonomic information used in this study, reflecting the likely influence of phytoplankton taxa smaller than those typically captured by the CPR device in determining PCI (Batten et al. 2003). The only significant correlations between biological and physical parameters were between PCI and SST for region B5 $(r=0.18)$ and C5 $(r=$ -0.18 ), and for phytoplankton community composition and MLD in region B5 $(r=-0.14)$. Although statistically significant links were found in these few instances, the correlation coefficients were relatively low and showed no consistent response of PCI to environmental forcing. Overall, the Mantel tests revealed weak to no relationships between the 3 physical parameters (SST, MLD and NAO) and the interannual variability of the biological datasets.

Examination of the contributions of different taxa to the community throughout the study period revealed few temporal changes, with the clear exceptions of the dominance of $R$. styli- plankton community composition between 1969 and 2013 for all 4 regions of the North-East Atlantic (Fig. 5). The greatest changes in community composition occurred in region B5 during 1988, and region C5 in 1993. Taxon level examination of the data revealed that temporal changes in these 2 regions were caused by a large increase in the abundance of 2 diatom taxa: Rhizosolenia styliformis in region B5 and Thalassiosira spp. in region C5. Although there were peaks in the Bray-Curtis dissimilarity coefficient, all regions after 1994 returned to a level of interannual variability no greater than 0.05 , representing only relatively small fluctuations in community composition over time (Fig. 5).

Mantel tests revealed very little correlation between phytoplankton community composition, PCI and the physical parameters over the study period. Only 3 instances resulted in correlations that were

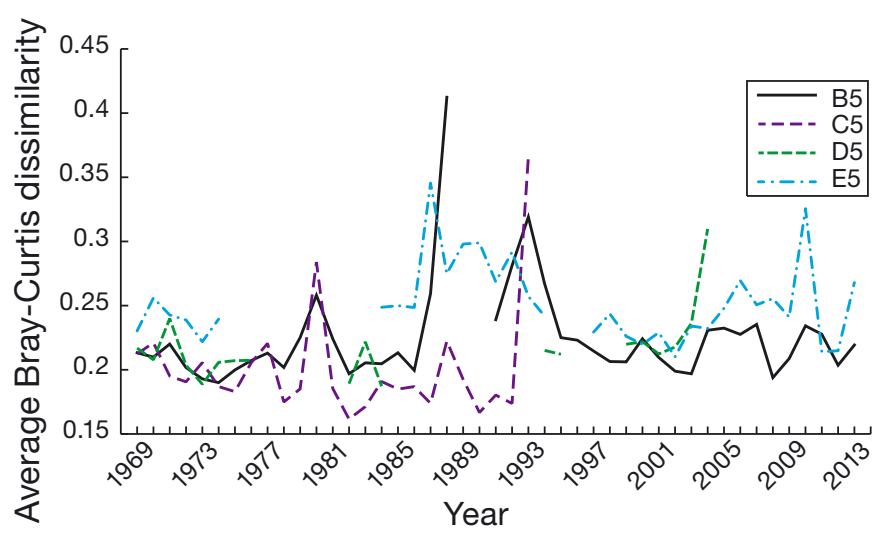

Fig. 5. Community composition, represented by Bray-Curtis dissimilarity coefficients for each Continuous Plankton Recorder (CPR) region over the study period 1969-2013. BrayCurtis values range from 0 (a community identical to other years) to 1 (a community entirely different to other years) 
formis in region B5 during 1988, and Thalassiosira spp. in region C5 during 1993. The dinoflagellate assemblage across all 4 study regions was dominated by the genus Ceratium, particularly $C$. fusus and $C$. furca, while the diatom assemblage was dominated by the genus Thalassiosira. The low interannual variability in composition between 1969 and 2013 suggests that the phytoplankton community composition in the North-East Atlantic remained largely stable, with a change in the key dominant taxa occurring between 1985 and 1995 before returning to its original state.

Ecological resilience $\left(1-\rho_{1}\right)$ and variance metrics $(V)$ applied to the biological data represent the stability of the phytoplankton community in the NorthEast Atlantic and its ability to return to community equilibrium after perturbation. Ecological resilience values $\left(1-\rho_{1}\right)$ were predominantly close to 0 for all 4 regions, indicating a capacity for communities to return quickly to equilibrium following a disturbance in composition (Table 2). The phytoplankton community composition of region B5 was found to be the most stable, with a resilience value of only 0.0001 (Table 2). The resilience value for region D5 was exceptionally high compared to all other regions (0.4618) and may be the slowest to return to equilibrium following a perturbation. The ecological variability experienced across the North-East Atlantic was very similar in all regions (Table 2).

The most abrupt change in disorder $\left(D_{0}\right)$ occurred in region B5 around 1995, with a greater than 2-fold increase in disorder at a time of rising biodiversity $\left(N_{2}\right)$ (Fig. 6) and taxa richness ( $R$, not shown here). Region E5 had 2 increases in disorder, the first in 1977 with return to low values of disorder before a second increase in 1997 (Fig. 6). The decline of disorder values after each dramatic increase demonstrates that the community consistently returns towards a stable state (Fig. 6). Such a return further supports the results of the ecological resilience test that demonstrated the ability of phytoplankton to

Table 2. Results of ecological resilience $\left(1-\rho_{1}\right)$ and ecological variance $(V)$ for averaged Bray-Curtis values, across each region of the North-East Atlantic

\begin{tabular}{|ccc|}
\hline & $\begin{array}{c}\text { Ecological resilience } \\
\left(1-\rho_{1}\right)\end{array}$ & $\begin{array}{c}\text { Ecological variance } \\
(V)\end{array}$ \\
\hline B5 & 0.0001 & 0.1817 \\
C5 & 0.0165 & 0.1947 \\
D5 & 0.4618 & 0.1604 \\
E5 & 0.0026 & 0.1705 \\
\hline
\end{tabular}

return quickly to equilibrium following perturbation (Table 2).

Sequential correlations were calculated on the first differences of disorder with biodiversity and with species richness, to seek insight into the role of community composition in population dynamics (Fig. 7). Regions B5 and E5 showed a switch in the sign of sequential coefficients of correlation on first differences from 1997 onwards, to a more negative correlation between disorder and taxa richness for B5 (Fig. 7a), and to a more positive correlation between disorder and biodiversity for E5 (Fig. 7d). These switches show recent samples in B5 undergoing a sustained period of ordered accumulations and disordered losses of taxa, consistent with endogenous competition; in contrast, recent samples in E5 undergo a sustained period of more ordered losses of taxa and disordered accumulations, consistent with exogenous forcing. Samples C5 and D5 show little change in correlation coefficient, except in the most recent samples which calculate coefficients from the fewest replicates (Fig. 7b,c).

\section{DISCUSSION}

\subsection{Interannual variability of phytoplankton community structure}

This study provides new insight into the consequences of changes to the physical environment for phytoplankton community structure in the NorthEast Atlantic at a taxon level. Bray-Curtis analysis demonstrated that the community remained relatively stable between 1969 and 2013, regardless of the variability observed in the physical environment (Figs. 3 \& 4). In region B5 during 1988, and region C5 in 1993, the community composition temporarily veered away from its equilibrium due to a substantial increase in the abundance of 2 centric diatom taxa, Rhizosolenia styliformis in region B5 and Thalassiosira spp. in region C5 (Fig. 5). However, we found no links with the physical environment to explain these years of dramatic community change.

The lack of long-term trends in taxa composition despite the observed increase in SST could potentially be explained by the fact that the majority of the taxa in this region have large thermal ranges, many of which span the annual and interannual averages of SST for each region, as well as the large seasonal variability found in this region (Irwin et al. 2012, Barton et al. 2013). The community could thus be well adapted to withstand the changes in annual mean 
B5

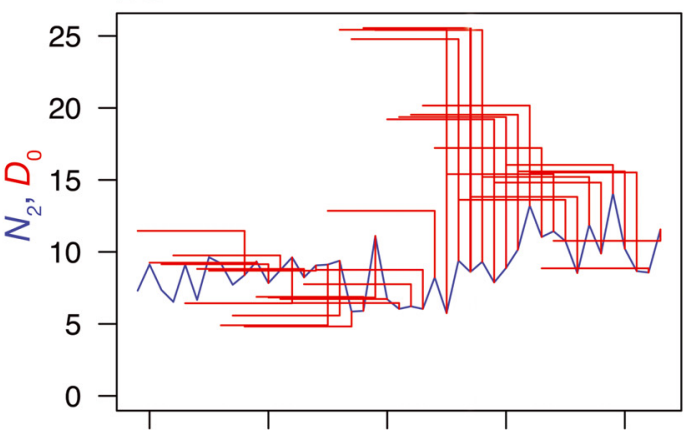

D5

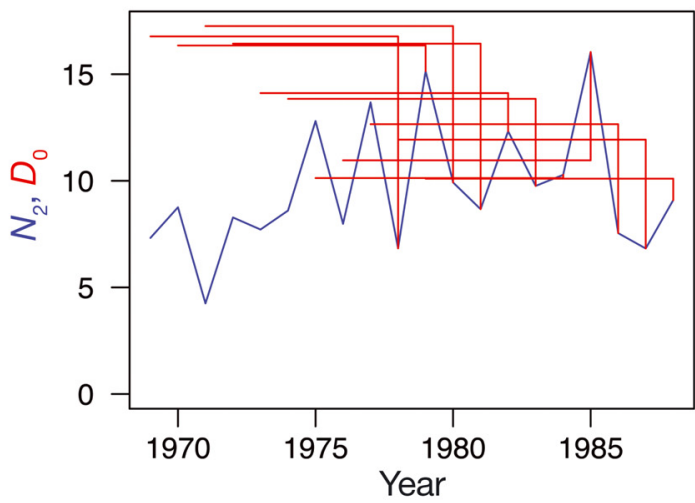

C5

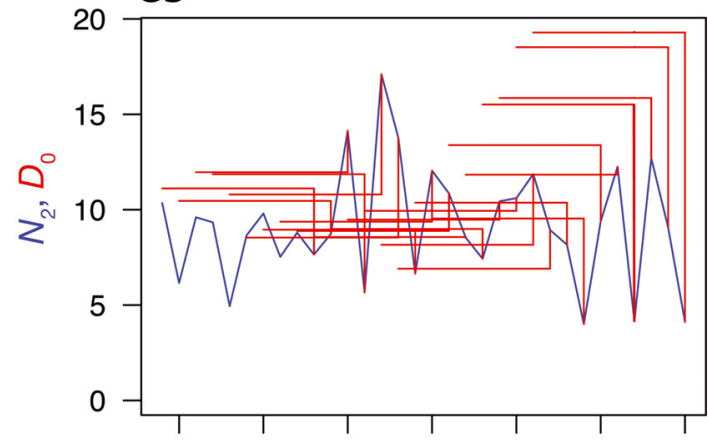

E5

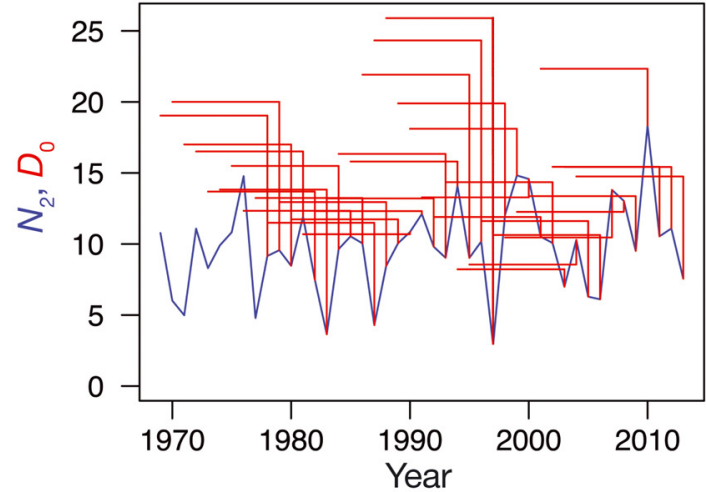

Fig. 6. Results of disorder analysis for regions B5, C5, D5 and E5. Each plot displays the time series of disorder ( $D_{0}$, red) and biodiversity $\left(N_{2}\right.$, blue). Each red line joins the disorder value to its corresponding biodiversity value (vertical part), and stretches back through the 10 time steps used for calculation of disorder (horizontal part). Note the different scales on each $y$-axis

SST observed in the North Atlantic, leading to a weak coupling between community structure and the physical environment over interannual timescales.

The dominant community members, such as $R$. styliformis and Thalassiosira spp., have cosmopolitan distributions spanning large areas of the North Atlantic and thus are expected to have a large thermal range, which is further evidence that broad temperature tolerance is important for phytoplankton community stability (Barnard et al. 2004, Barton et al. 2016). For example, the dinoflagellate composition proved to be highly stable in terms of taxa dominance, with Ceratium fusus dominant amongst our observed taxa throughout the time series for areas B5, C5 and D5. C. fusus has a wide biogeographic distribution (Barnard et al. 2004, Beaugrand 2004), large thermal range (Irwin et al. 2012, Barton et al. 2013) and is mixotrophic, which potentially allows this taxon to remain dominant under changing SST conditions through inter-specific competition with other taxa (Barnard et al. 2004). Similarly, the observed diatoms were dominated by the genus Thalassiosira, which also has a broad biogeographical range (Barnard et al. 2004, Beaugrand 2004, Richardson et al. 2006).

The disorder analysis provided a unique assessment of phytoplankton community composition in terms of structural rigidity and predictability over the study period. Changes in disorder demonstrated fluctuations in the relative dominance of persistent taxa over ephemeral taxa in the community, with the most abrupt change occurring in region B5 around 1995, with an increase in disorder at a time of rising biodiversity (Fig. 6). Supporting prior dominance analysis, C. fusus and Thalassiosira spp. may be 'keystone' taxa to the community structure, i.e. taxa that dominate the community regardless of the physical environment by occupying wide niches. Sequential correlations suggested a high turnover of ephemeral taxa in more recent years, in favour of more persistent and potentially competitively dominant taxa. As no large or persistent shifts were detected in the community over the studied time period, ecological theory suggests that the structural rigidity of the community may increase over time with an increasing prevalence of competitively dominant taxa, reducing richness, 

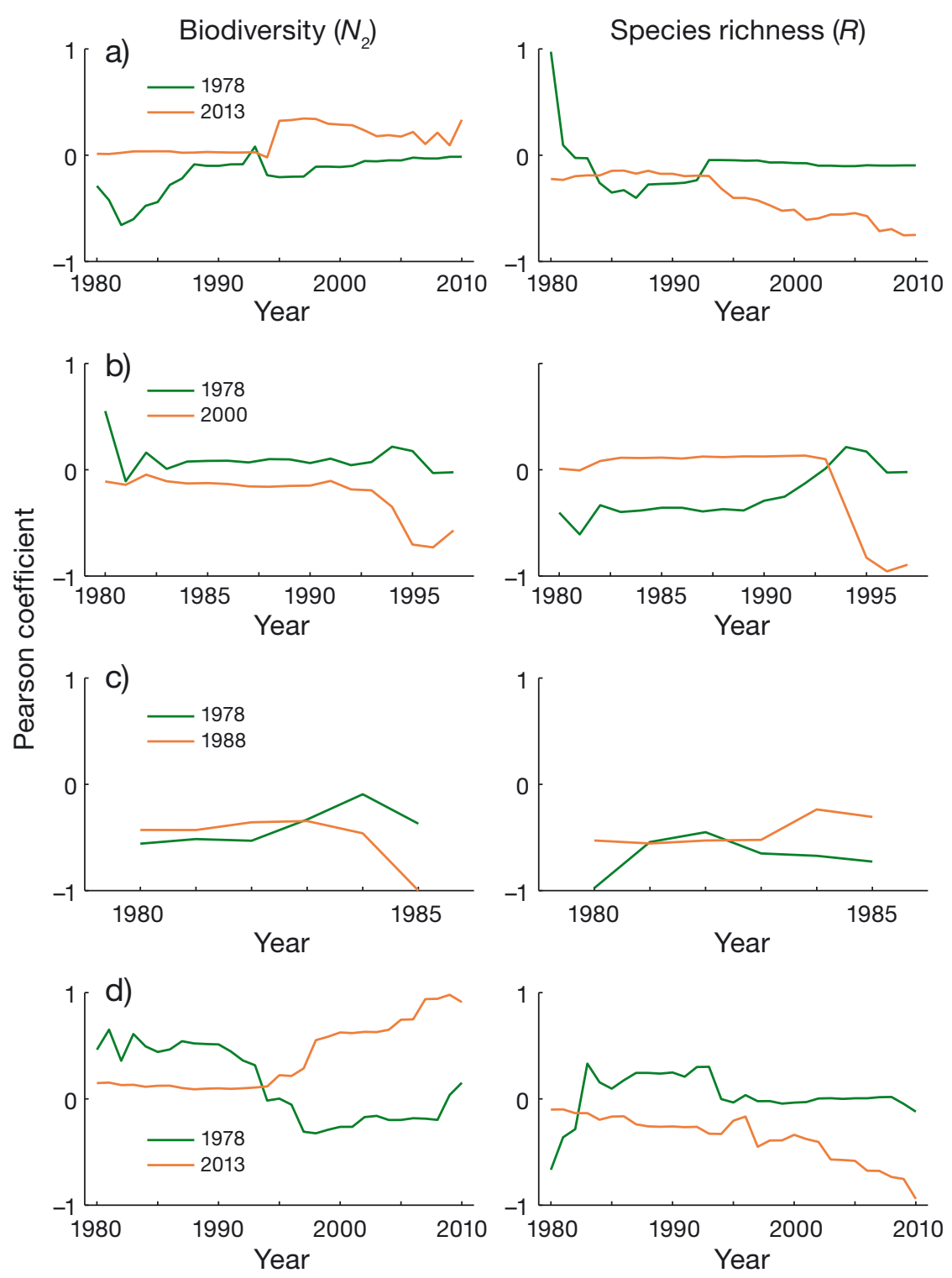

Fig. 7. Sequential product-moment correlations calculated on first differences of disorder $\left(D_{0}\right)$ with biodiversity $\left(N_{2}\right)$ and taxa richness $(\mathrm{R})$ for each Continuous Plankton Recorder (CPR) standard area: (a) B5, (b) C5, (c) D5 and (d) E5. Green trace calculates correlations backwards from the $x$-axis date to 1978 ; orange trace calculates correlations forward from the $x$-axis date to the most recent date. Switches in correlation between the green and orange trace indicate changes to the community composition

and may therefore render it more prone to collapse from external forcing (Doncaster et al. 2016).

The analysis of PCI across the North-East Atlantic demonstrates an increase in the mean that contrasts with the stability suggested by the Bray-Curtis community analysis (Figs. 3 \& 5). Previous studies have linked changes in phytoplankton community biomass, through the use of the PCI from the CPR survey and satellite derived chlorophyll a measurements, to changes in the physical environment over interannual timescales (Raitsos et al. 2005, McQuatters-Gollop et al. 2007a, Martinez et al. 2016). As a proxy for biomass, PCI allows insight into a greater proportion of the 'true' in situ phytoplankton community that was not fully taxonomically resolved in this study. The initial data manipulations that were conducted (as well as the mesh size of the CPR device and limitations of light microscopy) exclude many smaller and potentially less cosmopolitan taxa. Previous studies have reported a general decline in PCI until the late 1980s and then an increase beyond the 1990s, which tend to agree with the findings of our study (Fig. 3) (Edwards 2001, Beaugrand \& Reid 2003, Raitsos et al. 2014, Martinez et al. 2016). Future work should examine a larger proportion of the in situ community for taxa-based population changes, including taxa smaller than those captured by the CPR and taxa outside the diatom and dinoflagellate functional groups, and consider larger geographical regions.

\subsection{Implications for the bottom-up control of community structure}

The relationship between phytoplankton and the physical environment on interannual timescales has been widely debated (Dakos et al. 2009, Prowe et al. 2012, Barton et al. 2015); however, the weak correlations between the physical environment and community composition in this study were unexpected and largely contrasted with the outcomes of prior studies. Beaugrand \& Reid (2003) suggested that an increase in global temperatures would lead to a marked change in the organisation of phytoplankton communities within the North Atlantic, and such links have been demonstrated in studies showing that dinoflagellates dominate over diatoms in warmer SST regimes (Leterme et al. 2005, Henson et al. 2012, van de Poll et al. 2013). The influence of the NAO on the marine environment across the North Atlantic has also been well documented (Barton et al. 
2003, Drinkwater et al. 2003, Henson et al. 2012). The effect on phytoplankton is suggested to be that diatoms dominate in positive NAO years when conditions create a cooler climate, with stronger wind stress and deeper mixed layers, whereas during negative NAO periods (where the reverse conditions occur), dinoflagellates dominate (Edwards 2001, Henson et al. 2009, 2012). Increased temperatures were suggested to also cause a reduction in the overall cell size of the phytoplankton community and reduce the ecological diversity in warmer regions (Edwards et al. 2013). However, our Mantel test results found that for this region of the North-East Atlantic between 1969 and 2013, the phytoplankton community remained relatively stable with little change in composition, despite an increase in SST. Furthermore, when changes did occur, such as in region B5 during 1986, the community soon returned to its original state (Fig. 5).

Our analysis of the PCI time series revealed structural changes for each region throughout the studied time series, in agreement with the interannual analysis of Barton et al. (2015). In their study, the authors suggested that physical changes in the environment in the North-East Atlantic (surface wind speed, heat flux, SST, MLD, stratification and turbulent kinetic energy) were strongly related to phytoplankton on seasonal timescales but had little influence on the long-term (interannual) structure of phytoplankton communities.

As interannual fluctuations in community structure were not statistically linked to changes in the physical environment, we speculate that the variability of phytoplankton populations on interannual timescales may be driven by other factors, e.g. chaotic variability (Dakos et al. 2009, Barton et al. 2015). Dakos et al. (2009) utilised a model to describe variability of phytoplankton over seasonal and interannual timescales without the requirement for external forcing. Interannual variability within the phytoplankton population was found to be a naturally occurring property of multi-taxa communities, with chaotic fluctuations occurring frequently without environmental perturbation (Dakos et al. 2009). Population chaos has also been demonstrated in mesocosm experiments in which community fluctuations occur without external forcing (Benincà et al. 2008). The results of the Mantel test determined that there was no relationship between the phytoplankton community structure and changes to the physical environment. However, variability in the community may have resulted from the chaotic nature of a multi-taxa phytoplankton community, and this could be the driver of community fluctuations on interannual scales (Dakos et al. 2009).

\subsection{Stability of phytoplankton in the North-East Atlantic}

The apparent stability of the phytoplankton community in the North-East Atlantic identified by our analysis suggests that the community is well suited to the environmental perturbations occurring within the study period. When multiple taxa are well adapted to withstand environmental perturbations, we can expect a community to remain stable throughout time as demonstrated by the North Atlantic community examined here (Colebrook 1982, Leterme et al. 2005, Beaugrand et al. 2008). Taxa thermal ranges and biogeographical distributions reported in the literature show that the majority of taxa enumerated in the CPR survey have a large thermal tolerance that spans across the total SST variability from region B5 to E5, likely reducing their susceptibility to population change due to variable SST (Irwin et al. 2012, Barton et al. 2013). Coupled with this, the prevalence of other sources of interannual variability, including the $\mathrm{NAO}$, may contribute to the broad distribution of taxa across the North Atlantic and the resilience of the community to environmental change. The robustness of the phytoplankton community to long-term change in the physical environment has also been demonstrated in the fossil record, assessed with Bray-Curtis analysis (Cermeño et al. 2010), where the biodiversity and community structure of marine diatoms were found to recover after significant environmental perturbations. Cermeño et al. (2010) suggested that the high dispersal of marine phytoplankton, resulting in large biogeographical distributions, ensured the survival and recovery of the community (Cermeño \& Falkowski 2009, Cermeño et al. 2010).

The observed stability and predictability of the community contrasts with the results from some model studies, which predict that continued global warming will alter the phytoplankton community composition (Barton et al. 2010, Bopp et al. 2013, Dutkiewicz et al. 2015). For example, Barton et al. (2016) demonstrated that phytoplankton communities appear poised for a biogeographical shift and community re-shuffle in the dominance of key members in the second half of the $21^{\text {st }}$ century. The shift was predicted to result in decreased taxa richness in sub-tropical regions and an increase in sub-polar regions, as only approximately $35 \%$ of local taxa survive in future environmental conditions (Barton et al. 2016). The BrayCurtis analysis and stability metrics shown here demonstrate that even with changes to the physical environment, the community was able to return to its original state after perturbation, suggesting that 
larger temporal and spatial studies may be required to detect significant shifts in community composition linked to changes in the physical environment, and may become more evident in the future with the continued pressure of global climate change on the marine environment.

The findings here also contrast with results from the North Sea region, where a regime shift in the 1980s resulted in an increase in PCI values which was linked to increased SST (McQuatters-Gollop et al. 2007b, Raitsos et al. 2014). The North Sea is a relatively closed basin and is shallower than the NorthEast Atlantic, which may increase the impact of changes to the physical environment compared to a more open ocean basin. The regime shift described in the North Sea was also detected in PCI, which encompasses information from a greater proportion of the in situ community. Changes in the phytoplankton community may therefore be occurring in the smaller size fraction not captured in our study (McQuattersGollop et al. 2007b, Raitsos et al. 2014), and the relationship with the physical environment may be more complex; we therefore suggest that non-linear relationships should be examined in a future study. While a regime shift was not detected in the North-East Atlantic, the results of the disorder analysis highlighted the potential for future shifts in the community structure, as some areas of the present community appear to become increasingly rigid towards the end of the time series (Doncaster et al. 2016).

\section{CONCLUSION}

The findings presented here suggest that the mechanisms driving long-term ecological change in phytoplankton community composition within the North-East Atlantic are highly complex and perhaps more uncertain than previously described. The temporal and spatial extent of the CPR survey allows for a unique insight into the long-term variability of phytoplankton communities in the North-East Atlantic due to its unchanged methodology and consistent taxonomic detail. We found little or no correlation between diatom and dinoflagellate community composition and SST, MLD or the NAO index.

There was a change in the community composition between 1985 and 1995 from its initial state due to an increased dominance of 2 diatom taxa; however, after this period the community returned to its previous composition. As such, the diversity of the community remained relatively unchanged over the time series despite a shift to increased SST in the mid-1990s.
This stability was confirmed by tests of ecological resilience, which revealed high resilience of community composition over the time series. The resilience may be explained by the fact that the majority of taxa identified by the CPR have thermal tolerances greater than the environmental variability experienced. Disorder analysis, however, suggested a recent increase in structural rigidity in some communities, which may be an early warning signal to an eventual community collapse, and should be investigated in a future study. This study examined changes in the diatom and dinoflagellate fraction of the phytoplankton community captured by the CPR survey. We recognise that the community assessed here does not contain the smaller size fraction of the in situ phytoplankton community, which may manifest different patterns of variability than the larger size fraction captured by the CPR survey.

To conclude, our analysis demonstrates the ability of the phytoplankton community to return quickly to equilibrium composition after environmental perturbation, with a relatively stable community composition between 1969 and 2013 in the North-East Atlantic. With no clear relationship with the physical environment, we suggest that interannual variability in phytoplankton community composition may be driven by other factors, including internal community forcing such as chaos (Dakos et al. 2009), and it is therefore important that non-linear relationships are considered in future studies.

Acknowledgements. Our thanks go to the past and current members of the Marine Biological Association (formally the Sir Alister Hardy Foundation for Ocean Science) for establishing and maintaining the Continuous Plankton Recorder survey. This work is supported by the National Environmental Research Council, studentship number NE/L002531/1 and a Marine Biological Association associate researcher grant.

\section{LITERATURE CITED}

Anderson MJ, Crist TO, Chase JM, Vellend M and others (2011) Navigating the multiple meanings of beta diversity: a roadmap for the practicing ecologist. Ecol Lett 14: $19-28$

Barnard R, Batten SD, Beaugrand G, Buckland C and others (2004) Continuous plankton records: plankton atlas of the North Atlantic Ocean (1958-199). II. Biogeographical charts. Mar Ecol Prog Ser Suppl:11-75

Barton AD, Greene CH, Monger BC, Pershing AJ (2003) The Continuous Plankton Recorder survey and the North Atlantic Oscillation: interannual- to multidecadal-scale patterns of phytoplankton variability in the North Atlantic Ocean. Prog Oceanogr 58:337-358

Barton AD, Dutkiewicz S, Flierl G, Bragg J, Follows M (2010) Patterns of diversity in marine phytoplankton. Science 327:1509-1511 
Barton $\mathrm{AD}$, Finkel ZV, Ward BA, Johns DG, Follows MJ (2013) On the roles of cell size and trophic strategy in North Atlantic diatom and dinoflagellate communities. Limnol Oceanogr 58:254-266

Barton AD, Lozier MS, Williams RG (2015) Physical controls of variability in North Atlantic phytoplankton communities. Limnol Oceanogr 60:181-197

Barton AD, Irwin AJ, Finkel ZV, Stock CA (2016) Anthropogenic climate change drives shift and shuffle in North Atlantic phytoplankton communities. Proc Natl Acad Sci USA 113:2964-2969

Batten SD, Clark R, Flinkman J, Hays G and others (2003) CPR sampling: the technical background, materials and methods, consistency and comparability. Prog Oceanogr 58:193-215

Beaugrand G (2004) Continuous plankton records: plankton atlas of the North Atlantic Ocean (1958-1999). I. Introduction and methodology. Mar Ecol Prog Ser Suppl:3-10

Beaugrand G, Ibañez F (2002) Spatial dependence of calanoid copepod diversity in the North Atlantic Ocean. Mar Ecol Prog Ser 232:197-211

Beaugrand G, Reid PC (2003) Long-term changes in phytoplankton, zooplankton and salmon related to climate. Glob Change Biol 9:801-817

Beaugrand G, Edwards M, Brander K, Luczak C, Ibanez F (2008) Causes and projections of abrupt climate-driven ecosystem shifts in the North Atlantic. Ecol Lett 11: 1157-1168

Beaulieu C, Killick R (2018) Distinguishing trends and shifts from memory in climate data. J Clim 31:9519-9543

*Benincà E, Huisman J, Heerkloss R, Jöhnk KD and others (2008) Chaos in a long-term experiment with a plankton community. Nature 451:822-825

Boeing G (2016) Visual analysis of nonlinear dynamical systems: chaos, fractals, self-similarity and the limits of prediction. Systems 4:37-54

Bopp L, Resplandy L, Orr JC, Doney SC and others (2013) Multiple stressors of ocean ecosystems in the 21st century: projections with CMIP5 models. Biogeosciences 10: 6225-6245

Boyd PW, Strzepek R, Fu F, Hutchins DA (2010) Environmental control of open-ocean phytoplankton groups: now and in the future. Limnol Oceanogr 55:1353-1376

Bray JR, Curtis JT (1957) An ordination of the upland forest communities of southern Wisconsin. Ecol Monogr 27: 325-349

* Brun P, Vogt M, Payne MR, Gruber N and others (2015) Ecological niches of open ocean phytoplankton taxa. Limnol Oceanogr 60:1020-1038

Cermeño P, Falkowski PG (2009) Controls of diatom biogeography in the ocean. Science 325:1539-1541

Cermeño P, Dutkiewicz S, Harris RP, Follows M, Schofield O, Falkowski PG (2008) The role of nutricline depth in regulating the ocean carbon cycle. Proc Natl Acad Sci USA 105:20344-20349

Cermeño P, de Vargas C, Abrantes F, Falkowski PG (2010) Phytoplankton biogeography and community stability in the ocean. PLOS ONE 5:e10037

Chiswell SM (2011) Annual cycles and spring blooms in phytoplankton: Don't abandon Sverdrup completely. Mar Ecol Prog Ser 443:39-50

Chiswell SM, Bradford-Grieve J, Hadfield MG, Kennan SC (2013) Climatology of surface chlorophyll $a$, autumnwinter and spring blooms in the southwest Pacific Ocean. J Geophys Res Oceans 118:1003-1018
Clarke KR, Somerfield PJ, Gorley RN (2008) Testing of null hypotheses in exploratory community analyses: similarity profiles and biota-environment linkage. J Exp Mar Biol Ecol 366:56-69

Colebrook JM (1975) The continuous plankton recorder survey: automatic data processing methods. Bull Mar Ecol 8: 123-142

* Colebrook JM (1982) Continuous plankton records: seasonal variations in the distribution and abundance of plankton in the North Atlantic Ocean and the North Sea. J Plankton Res 4:435-462

*Dakos V, Beninca E, van Nes EH, Philippart CJ, Scheffer M, Huisman J (2009) Interannual variability in species composition explained as seasonally entrained chaos. Proc R Soc B 276:2871-2880

Dakos V, Carpenter SR, Brock WA, Ellison AM and others (2012) Methods for detecting early warnings of critical transitions in time series illustrated using simulated ecological data. PLOS ONE 7:e41010

* Dandonneau Y, Deschamps PY, Nicolas JM, Loisel H and others (2004) Seasonal and interannual variability of ocean color and composition of phytoplankton communities in the North Atlantic, Equatorial Pacific and South Pacific. Deep Sea Res II 51:303-318

*De Keersmaecker W, Lhermitte S, Honnay O, Farifteh J, Somers B, Coppin P (2014) How to measure ecosystem stability? An evaluation of the reliability of stability metrics based on remote sensing time series across the major global ecosystems. Glob Change Biol 20:2149-2161

*Doncaster CP, Chavez VA, Viguier C, Wang R and others (2016) Early warning of critical transitions in biodiversity from compositional disorder. Ecology 97:3079-3090

Drinkwater KF, Belgrando A, Borja A, Conversi A and others (2003) The response of marine ecosystems to climate variability associated with the North Atlantic. Geophys Monogr 134:211-234

* Dutkiewicz S, Follows M, Marshall J, Gregg WW (2001) Interannual variability of phytoplankton abundances in the North Atlantic. Deep Sea Res II 48:2323-2344

* Dutkiewicz S, Morris JJ, Follows MJ, Scott J, Levitan O, Dyhrman ST, Berman-Frank I (2015) Impact of ocean acidification on the structure of future phytoplankton communities. Nat Clim Change 5:1002-1006

Edwards M (2001) Long-term and regional variability of phytoplankton biomass in the Northeast Atlantic (19601995). ICES J Mar Sci 58:39-49

Edwards M, Richardson AJ (2004) Impact of climate change on marine pelagic phenology and trophic mismatch. Nature 430:881-884

*Edwards KF, Litchman E, Klausmeier CA, Elser J (2013) Functional traits explain phytoplankton community structure and seasonal dynamics in a marine ecosystem. Ecol Lett 16:56-63

Eggers SL, Lewandowska AM, Barcelos e Ramos J, BlancoAmeijeiras S, Gallo F, Matthiessen B (2014) Community composition has greater impact on the functioning of marine phytoplankton communities than ocean acidification. Glob Change Biol 20:713-723

Eppley RW (1972) Temperature and phytoplankton growth in the sea. Fish Bull 70:1063-1085

Follows M, Dutkiewicz S (2001) Meteorological modulation of the North Atlantic spring bloom. Deep Sea Res II 49: 321-344

Good SA, Martin MJ, Rayner NA (2013) EN4: quality controlled ocean temperature and salinity profiles and 
monthly objective analysis with uncertainty estimates. J Geophys Res 118:6704-6716

Henson SA, Dunne JP, Sarmiento JL (2009) Decadal variability in North Atlantic phytoplankton blooms. J Geophys Res 114:C04013

Henson SA, Lampitt R, Johns DG (2012) Variability in phytoplankton community structure in response to the North Atlantic Oscillation and implications for organic carbon flux. Limnol Oceanogr 57:1591-1601

Hill MO (1973) Diversity and evenness: a unifying notation and its consequences. Ecology 54:427-432

Hurrell JW (1995) Decadal trends in the North Atlantic Oscillation: regional temperatures and precipitation. Science 269:676-679

Hurrell JW, Kushnier Y, Otterson G, Visbeck M (eds) (2003) The North Atlantic Oscillation: climatic significance and environmental impact. Geophysical Monograph Series, Vol 134. American Geophysical Union, Washington, DC

Ingleby B, Huddleston M (2007) Quality control of ocean temperature and salinity profiles - historical and realtime data. J Mar Syst 65:158-175

* Irwin AJ, Nelles AM, Finkel ZV (2012) Phytoplankton niches estimated from field data. Limnol Oceanogr 57: 787-797

Killick R, Fearnhead P, Eckley IA (2012) Optimal detection of changepoints with a linear computational cost. J Am Stat Assoc 107:1590-1598

Killick R, Beaulieu C, Taylor S, Hullait H (2018) Detection of structural changes in climate and environment time series. Book Version: 1.1.1. R Package: EnvCpt. https://cran.rproject.org/web/packages/EnvCpt/index.html

Legendre P, Legendre LFJ (2012) Numerical ecology, Vol 24 (Developments in environmental modelling). Elsevier, Amsterdam

* Leterme SC, Edwards M, Seuront L, Attrill MJ (2005) Decadal basin-scale changes in diatoms, dinoflagellates, and phytoplankton color across the North Atlantic. Limnol Oceanogr 50:1244-1253

KLitchman E, Klausmeier CA, Miller JR, Schofield O, Falkowski PG (2006) Multi-nutrient, multi-group model of present and future oceanic phytoplankton communities. Biogeosci Discuss 3:607-663

Mantel N (1967) The detection of disease clustering and a generalized regression approach. Cancer Res 27:209-220

Martinez E, Raitsos DE, Antoine D (2016) Warmer, deeper, and greener mixed layers in the North Atlantic subpolar gyre over the last 50 years. Glob Change Biol 22:604-612

McQuatters-Gollop A, Raitsos DE, Edwards M, Attrill MJ (2007a) Spatial patterns of diatom and dinoflagellate seasonal cycles in the NE Atlantic Ocean. Mar Ecol Prog Ser 339:301-306

McQuatters-Gollop A, Raitsos DE, Edwards M, Pradhan Y, Mee LD, Lavender SJ, Attrill MJ (2007b) A long-term chlorophyll data set reveals regime shift in the North Sea

Editorial responsibility: Steven Lohrenz,

New Bedford, Massachusetts, USA

Reviewed by: 3 anonymous referees phytoplankton biomass unconnected to nutrient trends. Limnol Oceanogr 52:635-648

Oksanen J, Carvalho G (2013) Nestedness indices for communities of islands or patches. Vegan v. 2.5-6. https://github. com/vegandevs/vegan/blob/master/R/nestedtemp.R

Pimm SL (1984) The complexity and stability of ecosystems. Nature 307:321-326

* Prowe AEF, Pahlow M, Dutkiewicz S, Follows M, Oschlies A (2012) Top-down control of marine phytoplankton diversity in a global ecosystem model. Prog Oceanogr 101:1-13

R Core Team (2016) R: a language and environment for statistical computing. R Foundation for Statistical Computing, Vienna

* Raitsos DE, Reid PC, Lavender SJ, Edwards M, Richardson AJ (2005) Extending the SeaWiFS chlorophyll data set back 50 years in the northeast Atlantic. Geophys Res Lett 32:L06603

Raitsos DE, Pradhan Y, Lavender SJ, Hoteit I, McQuattersGollop A, Reid PC, Richardson AJ (2014) From silk to satellite: half a century of ocean colour anomalies in the Northeast Atlantic. Glob Change Biol 20:2117-2123

Reid PC, Colebrook JM, Matthews JBL, Aiken J, Team CPR (2003) The continuous plankton recorder: concepts and history, from plankton indicator to undulating recorders. Prog Oceanogr 58:117-173

* Richardson AJ, Walne AW, John AWG, Jonas TD and others (2006) Using continuous plankton recorder data. Prog Oceanogr 68:27-74

Rivero-Calle S, Gnanadesikan A, Del Castillo CE, Balch WM, Guikema SD (2015) Multidecadal increase in North Atlantic coccolithophores and the potential role of rising $\mathrm{CO}_{2}$. Science 350:1533-1537

Rodriguez-Girones MA, Santamaria L (2006) A new algorithm to calculate the nestedness temperature of presenceabsence matrices. J Biogeogr 33:924-935

Sommer U, Lengfellner K (2008) Climate change and the timing, magnitude, and composition of the phytoplankton spring bloom. Glob Change Biol 14:1199-1208

Thébault E, Fontaine C (2010) Stability of ecological communities and the architecture of mutualistic and trophic networks. Science 329:853-856

*van de Poll WH, Kulk G, Timmermans KR, Brussaard CPD and others (2013) Phytoplankton chlorophyll a biomass, composition, and productivity along a temperature and stratification gradient in the northeast Atlantic Ocean. Biogeosciences 10:4227-4240

Wang R, Dearing JA, Doncaster CP, Yang X and others (2019) Network parameters quantify loss of assemblage structure in human-impacted lake ecosystems. Glob Change Biol 25:3871-3882

Z Zhai L, Platt T, Tang C, Sathyendranath S, Walne A (2013) The response of phytoplankton to climate variability associated with the North Atlantic Oscillation. Deep Sea Res II 93:159-168

Submitted: October 15, 2019

Accepted: September 28, 2020

Proofs received from author(s): November 21, 2020 